\title{
Chimeric antigen receptor T cells for gamma-delta T cell malignancies
}

\author{
P. A. Wawrzyniecka ${ }^{1}$, L. Ibrahim ${ }^{1}$, G. Gritti $\mathbb{D}^{2}$, M. A. Pule $\mathbb{D}^{1}$ and P. M. Maciocia $\mathbb{D}^{1 凶}$
}

(c) The Author(s) 2021

Leukemia (2022) 36:577-579; https://doi.org/10.1038/s41375-021-01385-0

\section{TO THE EDITOR:}

Cancers derived from the malignant transformation of gamma-delta $(\gamma \delta) \mathrm{T}$ cells carry very poor prognosis. The major pathologies recognised are $\gamma \delta T$ acute lymphoblastic leukaemia ( $\gamma \delta$ T-ALL), and two lymphoma subtypes: hepatosplenic T cell lymphoma (HSTL) and primary cutaneous $\gamma \delta T$ cell lymphoma (PC $\gamma \delta-T C L)$ [1]. $\gamma \delta T-A L L$ represents approximately $10 \%$ of cases of T-ALL and is associated with high rates of induction failure, relapse and excess mortality [2]. HSTL is a rare (approximately $3 \%$ of cases of T cell lymphoma [1]) but highly aggressive disorder, which typically presents in males in the 2nd or 3rd decade of life, often in association with immunosuppressive therapy [3]. It carries the worst prognosis of all lymphoma subtypes, with a median survival of only 6-8 months [4] and only isolated cases of long-term survival [5]. PC $\gamma \delta-T C L$ is also rare (approximately $1 \%$ of skin lymphomas [1]) and presents with cutaneous involvement, typically associated with visceral and/or bone marrow disease. Again, outcomes are poor, with 75\% 1-year mortality in the largest published case series [6].

Treatment for $\gamma \delta$ malignancies is with cytotoxic chemotherapy, with no tumour-specific therapies currently available. By contrast, in analogous B-cell malignancies, highly effective immunotherapies, including monoclonal antibodies, bispecific $T$ cell engagers and chimeric antigen receptor (CAR)-T cells [7] are available. These therapies have revolutionised the treatment and outcome of advanced B-cell malignancies. CAR-T cells against CD19 in particular have demonstrated the potential to induce longlasting complete remissions even in patients with advanced and refractory cancers [7].

For $\gamma \delta$ malignancies, the defining immunophenotypic characteristic is expression of the $\gamma \delta$ T cell receptor (TCR), present in $>95 \%$ of cases of HSTL and in all PC $\gamma \delta-T C L$ and $\gamma \delta$ T-ALL [3]. Importantly, in normal tissues expression is limited to $\gamma \delta \mathrm{T}$ cells, where it functions as the antigen recognition receptor. Here, we developed CAR-T cells targeting the $\gamma \delta$ TCR and demonstrate in vitro and in vivo efficacy against $\gamma \delta$ T cell malignancies. Our data offers proof-of-concept for $\gamma \delta$ TCR-targeting with CAR-T cells as a potential approach to bring highly potent immunotherapy to the treatment of $\gamma \delta$ malignancies.

Primary $a \beta T$ cells were retrovirally transduced to express anti- $\gamma \delta$ TCR CAR or control anti-CD19 CAR (Fig. 1a). Following transduction with anti-CD19 CAR, a small proportion of $\gamma \delta$ T cells persisted in the culture, including some which expressed antiCD19 CAR. By contrast, for anti- $\gamma \delta$ TCR CAR, no $\gamma \delta$ T cells were detected in the culture, suggesting 'purging' of these cells by the transduced population (Fig. 1b). CAR-T cells were then co-cultured with $T$ cell lines which natively express (Loucy - V $\gamma 9 \mathrm{~V} \delta 2$, BE13 V $\gamma 8 \mathrm{~V} \delta 1, M O L T 13-V_{\gamma} 3 \mathrm{~V} \delta 1$ [8]) or are negative for surface $\gamma \delta \mathrm{TCR}$ (SupT1-CD19). While control anti-CD19 CAR lysed only SupT1CD19 cells, anti- $\gamma \delta$ TCR CAR-T lysed only $\gamma \delta$ TCR-positive cell lines (Fig. 1c). In addition, anti- $\gamma \delta$ TCR CAR-T cells demonstrated specific secretion of cytokines including interferon- $\gamma$, IL-2, IL-13 and TNF- $\alpha$ (Fig. 1d). Next, we co-cultured anti-CD19 or anti- $\gamma \delta$ CAR-T cells with normal autologous $\gamma \delta$ T cells. At a high E:T ratio (1:1), target normal $\gamma \delta T$ cells were partially lysed (Fig. 1e), with concomitant expansion of anti- $\gamma \delta$ CAR-T cells (Fig. 1f). A marked downregulation of $\gamma \delta$ TCR expression was noted on surviving $\gamma \delta$ T cells (Fig. 1g). Interestingly, by contrast, at lower E:T ratios (1:2 and 1:4), paradoxical $\gamma \delta$ T cell expansion was instead observed (Fig. 1e), associated with reduction in numbers of anti- $\gamma \delta$ CAR-T cells (Fig. 1f). This suggests lysis of anti- $\gamma \delta$ CAR-T by target normal $\gamma \delta$ T cells.

To assay the in vivo potency of anti- $\gamma \delta$ TCR CAR-T cells, we utilised the Loucy murine model of disseminated $\gamma \delta$ TCR-positive leukaemia (Fig. 2a, d). NSG mice were intravenously injected on CAR D-12 with $4 \times 10^{6}$ Loucy cells, engineered to stably express Firefly luciferase. Tumour engraftment was confirmed by bioluminescence imaging (BLI) at D-1 (data not shown), then mice were treated on D0 with $8 \times$ $10^{5}$ anti- $\gamma \delta$ TCR or control anti-CD19 CAR-T cells. Mice receiving anti$\gamma \delta$ TCR CAR demonstrated reduction of tumour burden, as assessed by flow cytometry of bone marrow and spleen at necropsy on D14 (Fig. 2b, c, Supplementary Fig. 1), BLI (Fig. 2e, f) and bleed at D30 (Fig. 2g). Prolonged survival (Fig. $2 \mathrm{~h}$ ) was seen in anti- $\gamma \delta$ TCR CAR recipients compared to CD19 CAR-treated animals, although all animals eventually died of progressive $\gamma \delta$ TCR-positive disease, with no evidence of antigen downregulation. In common with other NSG models, CAR-T cell persistence was limited, with no detectable cells in the peripheral blood at D30 (data not shown).

Despite success in B-cell malignancies, a lack of acceptable targets means targeted immunotherapy is rarely applied to $\mathrm{T}$ cell malignancies. The anti-CD30 antibody-drug conjugate

\footnotetext{
${ }^{1}$ Department of Haematology, Cancer Institute, University College London, London, UK. ${ }^{2}$ Hematology Department, Azienda Socio Sanitario Territoriale Papa Giovanni XXIII
} Hospital, Bergamo, Italy. ${ }^{凶}$ email: p.maciocia@ucl.ac.uk 
a

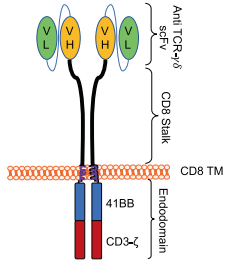

b

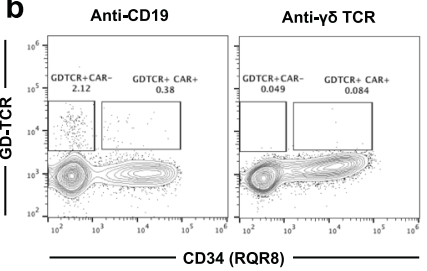

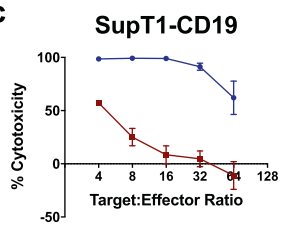

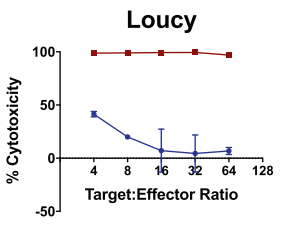

Loucy
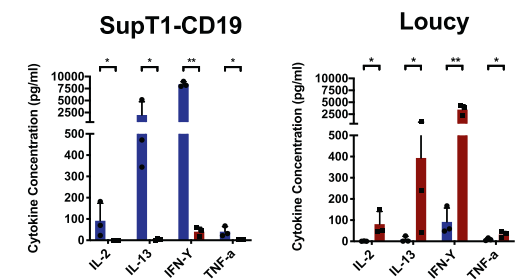
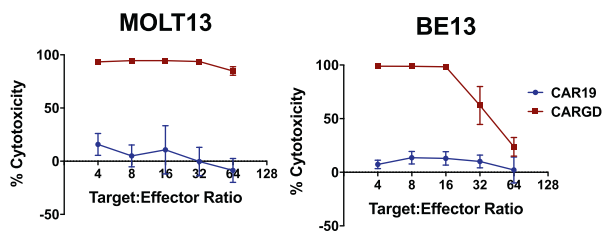

BE13
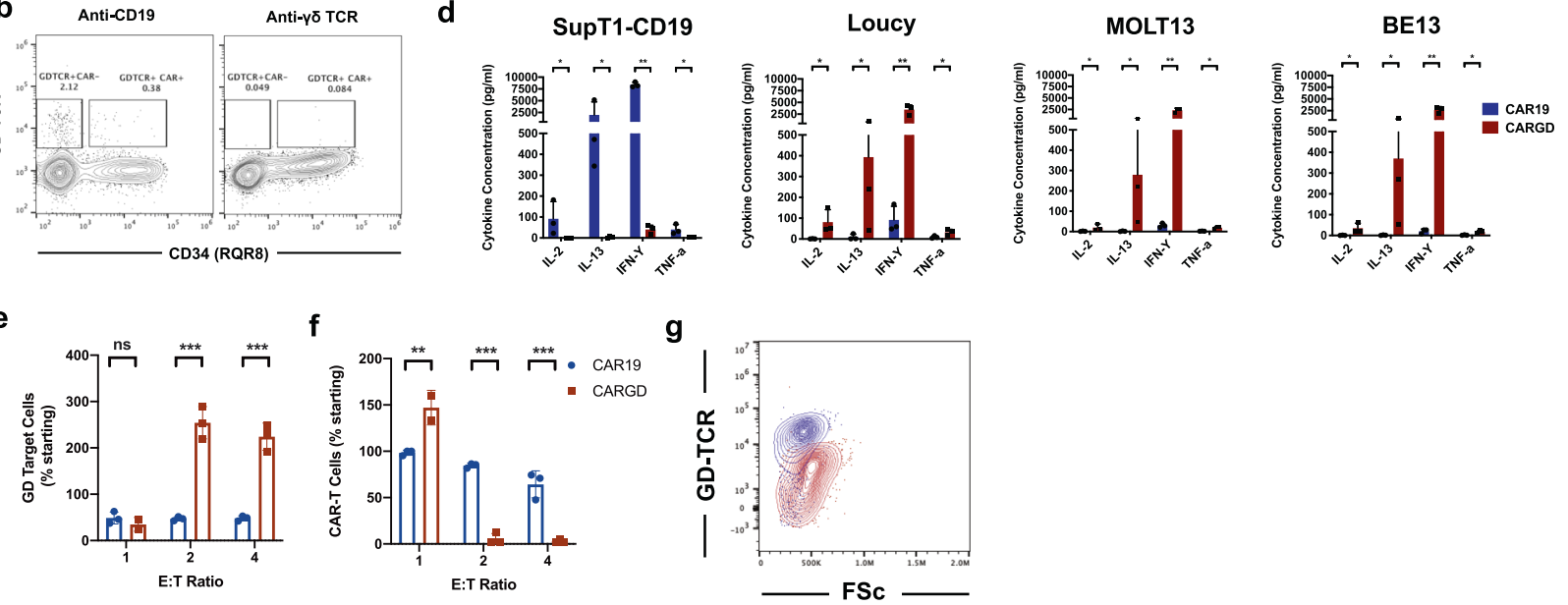

Fig. 1 In vitro testing of anti- $\gamma \delta$ TCR CAR. a Schematic of anti- $\gamma \delta$ TCR CAR, with 2nd generation architecture. b Example flow plot of $\gamma \delta-T C R$ staining on anti-CD19 or anti- $\gamma \delta$ TCR CAR-T cells following transduction c co-cultures of anti- $\gamma \delta$ TCR or control anti-CD19 CAR-T cells with CD19+ (SupT1-CD19) or $\gamma \delta$ TCR + cell lines (Loucy, MOLT13, BE13) (c) cytotoxicity at $72 \mathrm{~h}$, as measured by bioluminescence-based assay (d) cytokine secretion at $48 \mathrm{~h}$. e-g 120-h co-culture of control or anti- $\gamma \delta$ TCR CAR-T cells with autologous normal $\gamma \delta \mathrm{T}$ cells, $n=3$. e Residual $\gamma \delta$ T cells as proportion of starting cells $\mathbf{f}$ Example $\gamma \delta$ TCR staining on normal $\gamma \delta$ T cells after co-culture with anti- $\gamma \delta$ TCR CAR-T or anti-CD19 CAR-T cells $\mathbf{g}$ residual anti- $\gamma \delta$ TCR CAR-T or anti-CD19 CAR-T following co-culture, as proportion of starting cells. ${ }^{* *} p<0.001,{ }^{* * *} p<0.0001$.

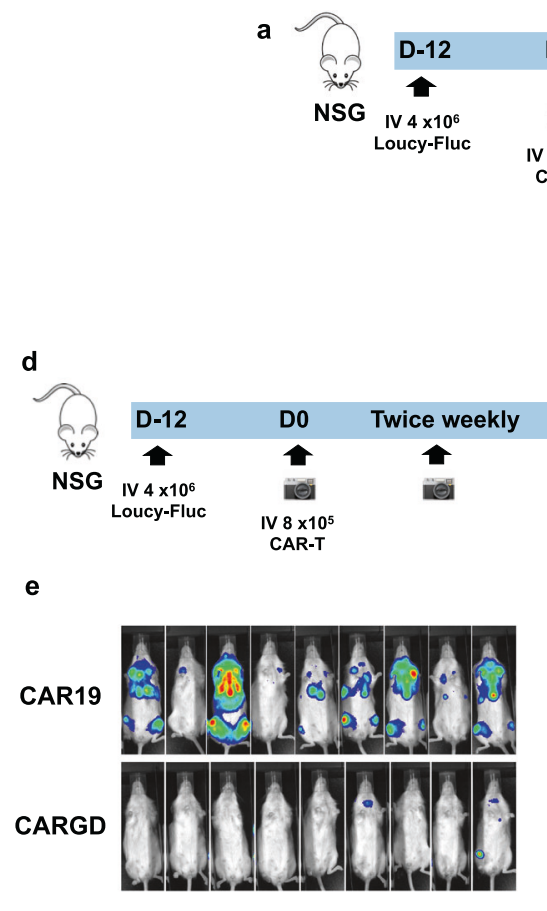

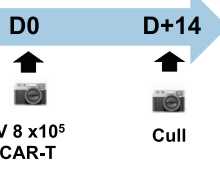
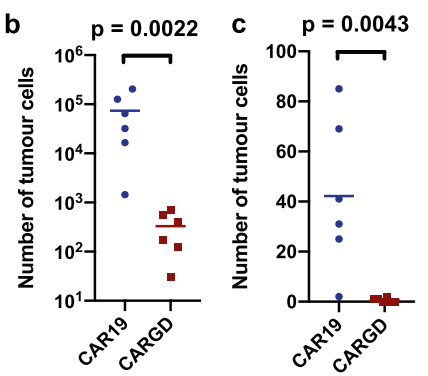

Fig. 2 In vivo assessment of anti- $\gamma \delta$ TCR CAR. a Schematic of Loucy murine model ( $n=6 /$ group) b Quantification of tumour in (b) marrow and (c) spleen at D14 following CAR-T injection. $\mathbf{d}$ Schematic of Loucy murine model ( $\mathrm{n}=9 / \mathrm{group}$ ) e bioluminescence (BLI) imaging at $\mathrm{D} 21$ following CAR-T infusion. $\mathbf{f}$ Quantification of BLI signal at D21 $\mathbf{g}$ quantification of tumour burden in blood at D30 $\mathbf{h}$ survival curves of mice (median survival CAR19 50 days $v$ CAR $\gamma \delta 69$ days, HR 12.4, $p=0.0003$, comparison by log-rank method). All other comparisons by Mann-Whitney $U$ test. 
brentuximab vedotin is effective in anaplastic large cell lymphoma [9], however, CD30 is not typically expressed in $\gamma \delta$ cancers [2]. Suggested approaches to targeting $\mathrm{T}$ cell malignancies include targeting pan-T cell antigens such as CD5 [10] or CD7 [11]. However, such strategies deplete the entire normal $T$ cell compartment and may induce profound immunosuppression [11], potentially requiring rescue by allogeneic hematopoietic stem cell transplant.

More refined approaches that target clonal elements of the TCR, such as selective targeting of TRBC1 and TRBC2 in a $\beta$ T cell malignancies, allow depletion of only part of the normal $T$ cell compartment [12]. While analogous approaches are potentially possible in $\gamma \delta$ TCR malignancies, simple targeting of the $\gamma \delta$ TCR may be feasible. This approach could concomitantly deplete normal $\gamma \delta$ T cells. These constitute $<5 \%$ of peripheral blood T cells, are more abundant in tissues and have a range of proposed ancillary immunological functions [13]. Importantly, genetically $\gamma \delta$-deficient mice display a very mild phenotype [14], and there is no known human pathology associated with $\gamma \delta$ T cell deficiency. This suggests that depletion of the $\gamma \delta \mathrm{T}$ cell compartment may be clinically tolerable, although initially clinical exploration of anti- $\gamma \delta$ TCR CAR-T should proceed cautiously: for instance with co-expression of a suicide gene [15], availability of back-up cryopreserved peripheral blood mononuclear cells, and close monitoring for development of atypical infections.

Indeed, it is unclear if anti- $\gamma \delta$ CAR-T treatment would lead to $\gamma \delta$ T cell aplasia. An interesting observation in our study was that, while anti- $\gamma \delta$ CAR-T expanded when cultured with normal $\gamma \delta$ T cells at high $E: T$ ratio, the reverse was observed when normal $\gamma \delta$ T was in excess. Thus, anti- $\gamma \delta$ CAR-T were themselves depleted from the culture, with expansion of normal $\gamma \delta T$ cells. The probable explanation is that CAR binding to the TCR of $\gamma \delta$ T cells induced CAR signalling, but also signalling via the TCR of the $\gamma \delta$ T cell, leading to a 2-way synapse with each cell potentially both target and effector. When normal $\gamma \delta T$ outnumbered anti- $\gamma \delta$ CAR-T, the balance of cytotoxicity resulted in anti- $\gamma \delta$ CAR-T cell lysis and expansion of the normal cells. The potential clinical consequences for anti- $\gamma \delta$ TCR CAR therapy are unclear and would be difficult to ascertain pre-clinically due to a lack of relevant immunocompetent models. However, in patients receiving anti- $\gamma \delta$ CAR-T, it is likely that the CAR-T: normal $\gamma \delta$ T cell ratio at the tumour site would be high in the critical initial CAR-T expansion phase, following lymphodepleting chemotherapy.

Here, we have demonstrated the feasibility of engineering normal $a \beta$ T cells to express anti- $\gamma \delta$ TCR CAR and have shown that anti- $\gamma \delta$ TCR CAR-T cells can specifically kill malignant $\gamma \delta$ cells both in vitro and in vivo. Our approach offers the first proposed strategy to bring highly potent CAR-T cells to the treatment of $\gamma \delta \mathrm{T}$ cell malignancies, where there is a major unmet need for effective therapies. Clinical assessment of this approach is warranted.

\section{REFERENCES}

1. Swerdlow SH, Campo E, Harris NL. WHO classification of tumours of haematopoietic and lymphoid tissues. Lyon; IARC; 2008.

2. Matos DM, Rizzatti EG, Fernandes M, Buccheri V, Falcão RP. Gammadelta and alphabeta $T$ cell acute lymphoblastic leukemia: comparison of their clinical and immunophenotypic features. Haematologica. 2005;90:264-6.

3. Tripodo C, lannitto E, Florena AM, Pucillo CE, Piccaluga PP, Franco V, et al. Gamma-delta T cell lymphomas. Nat Rev Clin Oncol. 2009;6:707-17.

4. Vose J, Armitage J, Weisenburger D. International T Cell Lymphoma Project. International peripheral T cell and natural killer/T cell lymphoma study: pathology findings and clinical outcomes. J Clin Oncol. 2008;26:4124-30.

5. Rashidi A, Cashen AF. Outcomes of allogeneic stem cell transplantation in hepatosplenic T cell lymphoma. Blood Cancer J. 2015;5:e318.

6. Willemze R, Jansen PM, Cerroni L, Berti E, Santucci M, Assaf C, et al. Subcutaneous panniculitis-like T cell lymphoma: definition, classification, and prognostic factors: an EORTC Cutaneous Lymphoma Group Study of 83 cases. Blood. 2008;111:838-45.
7. Grupp SA, Laetsch TW, Buechner J, Bittencourt H, Verneris MR, Boyer MW, et al. Analysis of a global registration trial of the efficacy and safety of CTL019 in pediatric and young adults with relapsed/refractory acute lymphoblastic leukemia (ALL). Blood. 2016;128:221.

8. Sandberg Y, Verhaaf B, van Gastel-Mol EJ, Wolvers-Tettero ILM, de Vos J, MacLeod RAF. et al. Human $T$ cell lines with well-defined $T$ cell receptor gene rearrangements as controls for the BIOMED-2 multiplex polymerase chain reaction tubes. Leukemia. 2007;21:230-7.

9. Horwitz S, O'Connor OA, Pro B, Illidge T, Fanale M, Advani R, et al. Brentuximab vedotin with chemotherapy for CD30-positive peripheral T cell lymphoma (ECHELON2): a global, double-blind, randomised, phase 3 trial. Lancet. 2019;393:229-40.

10. Mamonkin M, Rouce RH, Tashiro H, Brenner MK. A T cell-directed chimeric antigen receptor for the selective treatment of T cell malignancies. Blood. 2015;126:983-92.

11. Gomes-Silva D, Srinivasan M, Sharma S, Lee CM, Wagner DL, Davis $T H$, et al. CD7-edited $T$ cells expressing a CD7-specific CAR for the therapy of $T$ cell malignancies. Blood. 2017;130:285-96.

12. Maciocia PM, Wawrzyniecka PA, Philip B, Onuoha SC, Legut M, Sewell AK, et al. Targeting the $T$ cell receptor $\beta$-chain constant region for immunotherapy of $T$ cell malignancies. Nat Med. 2017;89:3909-12.

13. Vantourout $P$, Hayday A. Six-of-the-best: unique contributions of $\gamma \delta T$ cells to immunology. Nat Rev Immunol. 2013;13:88-100.

14. Fujihashi K. gamma/delta $T$ cell-deficient mice have impaired mucosal immunoglobulin A responses. J Exp Med. 1996;183:1929-35.

15. Philip B, Kokalaki E, Mekkaoui L, Thomas S, Straathof K, Flutter B, et al. A highly compact epitope-based marker/suicide gene for easier and safer $\mathrm{T}$ cell therapy. Blood. 2014;124:1277-87.

\section{ACKNOWLEDGEMENTS}

The authors would like to thank members of the Pule laboratory for help and advice.

\section{AUTHOR CONTRIBUTIONS}

PAW designed, performed and analysed the experiments and wrote the manuscript. $\mathrm{LI}$ assisted with in vitro experiments. GG provided reagents and samples. MAP wrote the manuscript and provided laboratory support. PMM conceived the idea, designed, performed and analysed experiments and wrote the manuscript.

\section{COMPETING INTERESTS}

PAW, LI and GG disclose no conflicts of interest. MAP is founder/chief scientific officer, and holds stocks/ equity in Autolus Ltd. PMM holds stocks in Autolus Ltd.

\section{ADDITIONAL INFORMATION}

Supplementary information The online version contains supplementary material available at https://doi.org/10.1038/s41375-021-01385-0.

Correspondence and requests for materials should be addressed to P.M.M.

Reprints and permission information is available at http://www.nature.com/ reprints

Publisher's note Springer Nature remains neutral with regard to jurisdictional claims in published maps and institutional affiliations.

\footnotetext{
Open Access This article is licensed under a Creative Commons Ac) Attribution 4.0 International License, which permits use, sharing,
adaptation, distribution and reproduction in any medium or format, as long as you give appropriate credit to the original author(s) and the source, provide a link to the Creative Commons license, and indicate if changes were made. The images or other third party material in this article are included in the article's Creative Commons license, unless indicated otherwise in a credit line to the material. If material is not included in the article's Creative Commons license and your intended use is not permitted by statutory regulation or exceeds the permitted use, you will need to obtain permission directly from the copyright holder. To view a copy of this license, visit http://creativecommons. org/licenses/by/4.0/.
}

(c) The Author(s) 2021 